\title{
Editorial for Special Issue "Applications of Artificial Intelligence and Machine Learning in Geotechnical Engineering"
}

\author{
Mark Jaksa ${ }^{1, *(1)}$ and Zhongqiang Liu ${ }^{2, *}$ \\ 1 School of Civil, Environmental and Mining Engineering, University of Adelaide, Adelaide, SA 5005, Australia \\ 2 Norwegian Geotechnical Institute, Sognsveien 72, 0855 Oslo, Norway \\ * Correspondence: mark.jaksa@adelaide.edu.au (M.J.); zhongqiang.liu@ngi.no (Z.L.)
}

check for

updates

Citation: Jaksa, M.; Liu, Z. Editorial for Special Issue "Applications of Artificial Intelligence and Machine Learning in Geotechnical Engineering". Geosciences 2021, 11, 399. https://doi.org/10.3390/ geosciences 11100399

Received: 14 September 2021 Accepted: 15 September 2021 Published: 22 September 2021

Publisher's Note: MDPI stays neutral with regard to jurisdictional claims in published maps and institutional affiliations.

Copyright: (c) 2021 by the authors. Licensee MDPI, Basel, Switzerland. This article is an open access article distributed under the terms and conditions of the Creative Commons Attribution (CC BY) license (https:// creativecommons.org/licenses/by/ $4.0 /)$.
Since its inception in the mid-1950s [1], artificial intelligence (AI) has become a disruptive and pervasive technology. Its reach continues to expand at an ever-increasing pace, with major contributions to areas such as optical character recognition, computer vision, speech recognition, medical diagnostics, defence, and autonomous vehicles. It is without doubt that AI will continue to grow in the future and will become far more routine than it is at present. Machine learning (ML) is a subset of AI and is the study of computer algorithms that automatically improve through experience. The most common form of ML are artificial neural networks (ANNs), which are computer surrogates of the human brain, which is a biological neural network. One of the first-if not the first-proponents of ANNs in geotechnical engineering was A. T. C. Goh, who published a paper in 1994 applying ANNs to the assessment of seismic liquefaction potential [2]. Since then, as outlined by Shahin et al. [3], ANNs have been applied extensively to a wide range of geotechnical engineering problems, with a considerable degree of success. In recent years, with the rapid development of ML and its spread over many engineering fields, many researchers have started looking into disciplinary or thematic applications of ML methods. In fact, ML and its derivatives, such as deep learning (DL), are particularly helpful in and relevant to geotechnical engineering, where data are often sparse, the variability of soils and rock can often be highly variable, and measurements-especially in situ-are influenced by measurement and model uncertainties.

This Special Issue includes eight original and hitherto unpublished works that focus on various aspects of "Artificial Intelligence and Machine Learning in Geotechnical Engineering." Rauter and Tschuchnigg [4] employed a range of ML techniques, i.e., ANN, support vector machine (SVM), and random forest (RF), to interpret cone penetration test (CPT) data with respect to soil classification. They found that both ANNs and the RF technique yielded very accurate predictions. Hernandez-Martinez et al. [5] and Yousefpour et al. [6] used ML to predict the stiffness and strength of stabilized organic soils. The authors observed that the ANN models yielded the highest predictive accuracy. Choi et al. [7] applied three ML algorithms (deep neural networks, RF, and SVM) to predict the leak-off pressure that is used during drilling in the petroleum industry. The authors found that all three of the algorithms yielded superior predictions to those obtained from multivariate linear regression. Mejri and Bekara [8] showed that ML greatly assists with the quality control of noisy seismic data obtained in the process of subsurface hydrocarbon prospecting.

It is particularly pleasing to see that this Special Issue presents further work by Prof. A. T. C. Goh and his co-workers on liquefaction assessment [9]. They applied several ML techniques-i.e., Ridge, Lasso and LassoCV, RF, extreme gradient boost (XGBoost), and multivariate adaptive regression splines (MARS) - to examine their efficacy in relation to liquefaction assessment. They found that the MARS, RF, and XGBoost methods performed the best. Crisp et al. [10] applied genetic algorithms to 2ptimize site investigations for the design of pile foundations. The authors concluded that, while boreholes arranged in a regular grid pattern provide good performance in many cases, there are situations 
where optimized locations provide a cost saving of $4.2 \%$ of the construction cost. Finally, Xie et al. [11] provides an extensive literature review of ML models for the predictive maintenance of railway tracks from a geotechnical engineering perspective. They conclude that ML models are able to avoid the unnecessary replacement of track components; save costs; and improve the safety, availability, and efficiency of railway service.

We are confident that you will find that these inspirational papers demonstrate the great potential of artificial intelligence and machine learning in augmenting traditional forms of geotechnical engineering analyses.

Conflicts of Interest: The authors declare no conflict of interest.

\section{References}

1. Crevier, D. AI: The Tumultuous Search for Artificial Intelligence; BasicBooks: New York, NY, USA, 1993; ISBN 0-465-02997-3.

2. Goh, A. Seismic Liquefaction Potential Assessed by Neural Networks. J. Geotech. Eng. 1994, 120, 1467-1480. [CrossRef]

3. Shahin, M.A.; Jaksa, M.B.; Maier, H.R. Artificial neural network applications in geotechnical engineering. Aust. Geomech. 2001, 36, 49-62.

4. Rauter, S.; Tschuchnigg, F. CPT Data Interpretation Employing Different Machine Learning Techniques. Geosciences 2021, 11, 265. [CrossRef]

5. Hernandez-Martinez, F.; Al-Tabbaa, A.; Medina-Cetina, Z.; Yousefpour, N. Stiffness and Strength of Stabilized Organic Soils-Part I/II: Experimental Database and Statistical Description for Machine Learning Modelling. Geosciences 2021, 11, 243. [CrossRef]

6. Yousefpour, N.; Medina-Cetina, Z.; Hernandez-Martinez, F.; Al-Tabbaa, A. Stiffness and Strength of Stabilized Organic Soils-Part II/II: Parametric Analysis and Modeling with Machine Learning. Geosciences 2021, 11, 218. [CrossRef]

7. Choi, J.; Liu, Z.; Lacasse, S.; Skurtveit, E. Leak-Off Pressure Using Weakly Correlated Geospatial Information and Machine Learning Algorithms. Geosciences 2021, 11, 181. [CrossRef]

8. Mejri, M.; Bekara, M. Application of Machine Learning for the Automation of the Quality Control of Noise Filtering Processes in Seismic Data Imaging. Geosciences 2020, 10, 475. [CrossRef]

9. Chen, Z.; Li, H.; Goh, A.; Wu, C.; Zhang, W. Soil Liquefaction Assessment Using Soft Computing Approaches Based on Capacity Energy Concept. Geosciences 2020, 10, 330. [CrossRef]

10. Crisp, M.; Jaksa, M.; Kuo, Y. Optimal Testing Locations in Geotechnical Site Investigations through the Application of a Genetic Algorithm. Geosciences 2020, 10, 265. [CrossRef]

11. Xie, J.; Huang, J.; Zeng, C.; Jiang, S.-H.; Podlich, N. Systematic Literature Review on Data-Driven Models for Predictive Maintenance of Railway Track: Implications in Geotechnical Engineering. Geosciences 2020, 10, 425. [CrossRef] 